\title{
Multi-Campus Colleges in South Africa: Challenging Capabilities of Principals in Managing Institutional Transformation
}

\author{
Dr Miranda N. Mgijima
}

University of South Africa (UNISA), College of Education, Department of Educational Leadership and Management mgijimm@unisa.ac.za / nomsomgjm4@gmail.com

\section{Doi:10.5901/mjss.2014.v5n14p394}

\begin{abstract}
Mergers, institutional reorganisation and the establishment of a network of multi-campus colleges in South Africa has served as a major policy trajectory to transform the post-schooling education and training sub-system under the current democratic dispensation. The changes have had a fundamental impact on the leadership capabilities of college principals and their management teams. This article draws upon findings of the training needs assessment study conducted in 2012 in the Further Education and Training colleges. From a systems thinking approach, the study tries to locate leadership development within the context of policies that undergird transformation. The study used the mixed method of inquiry and data were collected through questionnaires, focus group discussions and document analysis. A purposive sampling procedure was followed. The findings reveal an urgent need to equip managers with essential competences to lead effectively in a complex environment of constant change. The article concludes by suggesting integrating continuing professional development in the overall strategy of change and transformation, using learning communities as a mechanism to sustain effective leadership in the long-term.
\end{abstract}

Keywords:Capabilities, mergers; transformation; systems thinking; professional learning communities

\section{Introduction}

Since the advent of democracy in 1994, the provision of technical and vocational education has seen massive transformation. Through mergers, institutions were reorganised and fifty Further Education and Training (FET) multicampus colleges were established. New programmes and qualifications were introduced. Colleges were given greater autonomy and more functions were devolved. According to Gewer (2010:24), "today, many colleges are still struggling with the challenges associated with multi-campus management, with varying management capacity across campuses and unequal resources". In the Diagnostic Report (National Planning Commission, 2011), the FET college sector is criticised for providing vocational education and training that is limited in scale, scope, quality and relevance. Colleges are described as under-performing, unattractive, and offering second class education. This is a serious indictment on the leadership and management of these institutions. Compounding the problem has been the reform overload experienced during the past fifteen years within the FET college sector bringing much pressure on the already limited capabilities of principals.

This prompted the South African College Principals' Organisation (SACPO) to reflect on the competency profile of college managers given their expanded role of managing a network of multi-campuses. The reflection was "in terms of activities and interactions that are distributed across multiple people and situations, involving complementarities and network patterns of control (Timperley, 2005). Implied here was the need to review the blending of leadership responsibilities from the college principal and those leadership responsibilities delegated to the other members of the leadership teams (Watson, 2009:5). The review encompassed a training needs assessment (TNA) study conducted in 2012, commissioned by SACPO. The ultimate aim was to design evidenced-based continuing professional development (CPD) programmes. TNA is a process by which an organisation systematically investigates current and future learning requirements in relation to the operating environment. It seeks to determine the gap between existing knowledge, skills and abilities and those needed for the organisation to function at its optimum level (Mgijima, 2014).

This article reports on selected findings of the TNA study, drawing from perceptions of managers regarding their professional development needs. It locates the discussion within the policy trajectory that has shaped the systemic reforms since the release of the first education white paper of 1996. The study aims to contribute to the national discourse on how to improve the management and leadership capacity in the FET colleges. The fundamental question asked in the investigation was: what competences do college managers require to strengthen their capabilities and make 
them successful in a complex and dynamic environment?

\title{
2. Background Context
}

That the provision of vocational and technical training in the post-apartheid South Africa needed to be transformed cannot be disputed. According to the National Further Education and Training Plan, by 1995 South Africa had 152 technical colleges, located in the racially segregated education departments (Department of Education, 2008). Technical colleges differed regarding organisational structure, type, size, curricula and staff competence. They were governed, managed and funded in different ways depending on their location as determined by apartheid planning. Each college operated as a single business entity.

To initiate transformation, the Further Education and Training Act was promulgated, announcing a broad and longterm framework that would change curriculum programmes and qualifications, whilst introducing new funding and quality assurance mechanisms (Republic of South Africa, Act 98 of 1998). In 2000, the Department of Education (DoE) established the National Landscape Task Team to develop a national strategy for the re-organisation of the sector as well as the recapitalisation of the aging physical infrastructure. The Task Team recommended merging the 152 colleges to create 50 multi-campus public FET colleges, a significant move from a large number of single campus college model towards fewer, but larger and decentralised institutions.

The FET colleges deliver post-school vocational and technical education and training programmes to students who are 15 years and older. The rationale behind mergers was to improve quality and access, reduce duplication, raise standards, enhance relevance and responsiveness of programmes and make better use of available resources. The National FET Plan states that "colleges will be encouraged to develop themselves into niche institutions with specialist excellence in specific fields or disciplines. This will increase the quality of provision and improve cost-effectiveness" (2008: 47). The challenge therefore was to transform the racially-constructed colleges into a coherent system that would respond to the vocational education and training needs of the $21^{\text {st }}$ century.

The merged institutions may have up to eight campuses, each headed by a campus or programme manager. Additional to the principal, the organisational structure allows for a minimum of four deputy principals per college, responsible for: academic affairs; research and planning; corporate services and financial management. They constitute the college senior management team (SMT). When the SMT meets with campus and programme managers including Heads of Departments, they form the Broad Management Team (BMT). Organisationally therefore, management of college operations is a shared or distributed responsibility. However, the principal remains accountable for results regarding all business processes including: academic and financial administration, personnel and asset management. At issue is that very few, if any of the SMT or BMT members were prepared for the magnitude of change and the responsibilities it brought about in the FET sector.

At the FET college summit in August 2010, the Minister of Higher Education and Training commented:

\begin{abstract}
"We are aware of the many difficulties that have been experienced in recent years in the FET college subsystem as a result of a complex and incomplete transition, with multiple and overlapping changes of a profound nature for which many were ill-equipped".
\end{abstract}

This is the crux of the problem. As Meyer (2008:163) remarks, the "restructuring of many South African organisations in the past five years has brought with it huge training needs". The analysis of the performance of the public FET colleges shows a system that has remained fragile and unstable as a result of the complex transformation experienced over the past 15 years. In the final analysis, it is the confluence of transformation goals, systemic policies, economic demands and political expectations that have critically challenged the capabilities of management teams in these colleges. In the absence of professional standards for college principal-ship, what critical competences are most required for effective management in a changing environment?

\section{Change, Leadership and Systems Thinking}

The synopsis above shows that changes introduced to transform the FET colleges are of a systemic nature. Dalin (1978:22-23) suggested three characteristics of change: change as a process, change as a systemic phenomenon, and change as a multi-dimensional phenomenon. The college reform programme embraces all three with institutional reorganisation and merger constituting the major thrust of the change process. Harman and Meek (2002:1) argue that merger as "a policy issue has received a great deal of scholarly attention, a significant reason being because of the way 
national governments have used mergers to initiate systemic restructuring of education in post-schooling systems of education". A merger is defined "as a process whereby two or more formerly separate and independent ... education institutions become, legally and organisationally, a single entity under the managerial responsibility and control of a single governing body and a chief executive officer" (Harman, 1983:114).

Drawing on the experiences of countries like Australia and Norway, Skodvin claims that it is very difficult "to amalgamate previously independent colleges which were located in different places without creating large conflicts and demand for new management skills" (1997:323). Skodvin's argument stresses that such conflicts direct attention away from what colleges are actually supposed to do, namely teaching and research, which in turn results in qualitative stagnation of the institutions. He posits as a logical hypothesis that it will be more difficult to have collaboration and academic integration at network colleges than at colleges located in the same place, and the degree of difficulty will be proportional to the geographical distance between campuses. In his analysis, he argues that this does not only stunt the capacity to develop, but also leads to organisations that are dysfunctional, unproductive and failing to full-fill their mandates. This highlights challenges confronting managers in trying to create integrated communities from cultures that were historically uncomplimentary. The report cites examples where very different organisational and academic cultures collided, consequently becoming a potent and disintegrative force (Skodvin, 1997).

To avoid such unintended outcomes, the systems thinking approach stresses the need to mediate and control change, treating training and development of leaders as an inherent part of the planned change process. Citing the USA as an example where mergers have been successful, Harman and Robertson-Cunninghame (1995) argued that besides good technical infrastructure and sufficient supply of resources, another key success factor in the merger of institutions, is visible and strong leadership, which is capable of integrating different sub-cultures as well as creating a common feeling of identity. According to Kitching, the quality and realism of planning management capacity is also seen as one of the major determinants in successful merger outcomes and that one of the primary reasons why some mergers succeed is the "management expertise, particularly in the area of management of change" (in Harman 1983:17). The importance of leaders in managing change and innovation has been endorsed by other scholars as well (Volmari,et al, 2009: 41; Mgijima, 1991). The emphasis in the argument is that where culturally different institutions are brought together, expert leadership is needed in order to keep damaging cultural conflicts to a minimum and to develop within the newly created institution, academic vibrancy, new loyalties, high morale and a sense of community (Harman \& Meek, 2010:3).

In this regard, Hallinger and Heck (2011:12) stress the importance of a collaborative perspective on leadership where emphasis is gradually shifting from hierarchical positions to the distribution of leadership "among individuals holding a wider range of organisational roles". As the OECD Report (2008:32) elaborates, "school leadership can encompass people occupying various roles and performing various functions such as principals, deputy and assistant principals, leadership teams and governing boards". Leadership therefore is a "broader concept where authority to lead does not reside only in one person, but can be distributed among different people within and beyond the school". This is regarded as a new ideology of leadership, shifting focus from an individual towards one of shared expertise within a learning organisation. This new ideology means leadership that empowers managers, encouraging them to act independently in different situations (OECD, 2008:18) which is consistent with the new leadership arrangements arising from mergers that created the transformed FET colleges in South Africa. Where multiple sources of power exist, it becomes necessary to work as a collective for effective service delivery.

In other countries, candidates who aspire to take school headship positions must first "show that they have the appropriate level of school leadership and management knowledge, understanding and abilities to perform the tasks required of headship" (Bolam, 1997:265). In South Africa, such a requirement does not exist, making leadership training and continuing professional development (CPD) an imperative. CPD refers to on-going learning activities that take place as a planned, structured process, involving the assessment of development needs and designing training according in alignment with the changing operational environment Wilcox, 2010; Mgijima, 2014). As Watson (2009:6) pointed out, in the context of mergers, "leaders need specific training to respond to broadened roles and responsibilities". In South Africa, CPD programmes should be relevant for purposes of developing visionaries and innovators required for managing systemic changes.

Because distributed leadership calls for the development of organisational rather than individual competences, to be effective, CPD programmes should endorse the use of 'communities of learning' as a viable strategy. Gadja and Koliba (2007:27) stated that, "collaboration is almost universally valued as an essential element" of professional growth. In this sense, leadership must not just be distributed but it must be empowering to teams that take responsibility for the different parts of the organisation. Within the discipline of systems thinking, Senge (1990) provided a conceptual framework for linking individual to organisational learning, highlighting as the basis, progression from the individual, to group oriented practices underpinned by a shared vision and team learning as the frame. In this regard, Potter, Baron 
and Cioffi (2003:201) observed that Senge's work "gave a unified vision for achieving personal, work group and organisational effectiveness" because in a learning organisation, over a period of time workers become capable of expansion of capacities and of progressive joint learning.

Schoech (2004:1) observed that, "systems are nested in a hierarchy, that means systems consist of subsystems and systems operate within environments". Using this lens, the intention was to explain the relationships between the broader goal of the system to reorganise colleges into multi-campuses and the need to equip managers with the required competences to lead institutional reform at the sub-system level. It has been acknowledged that change in the sector happened due to political triggers at the macro-level. In this case, government laws and regulations were used to introduce change. Analysed from the systems perspective, it is clear that the case of transforming the FET colleges has encountered certain challenges. Failure to provide managers with the requisite knowledge and skills has possibly led to frustration, underperformance and lack of confidence. It is now realised that the administrative burden for principals has increased tremendously, requiring a different set of skills and knowledge to manage successfully. College managers, coming from a network of campuses need to work collaboratively, trust and engage each other in order to realise the organisational goals. For this, they need to improve their leadership capabilities through CPD programmes.

\section{Research Methodology}

This article reports selected findings from a large scale survey of the training needs of lecturers and managers in the FET colleges. The study, led by the author assisted by a senior researcher and two data analysts, was commissioned in 2012 by the South African College Principals' Organisation (SACPO). The study used the mixed method approach for "purposes of breadth and depth of understanding and corroboration" (Johnson, Onwuegbuzie and Turner, 2007:123). The aim was "to produce a more complete picture by combining information from complementary kinds of data or sources" (Denscombe, 2008:272). This was to secure an in-depth understanding of performance gaps and how these could be addressed through evidence-based continuing professional development programmes. A review of official government documents and existing literature from national and international studies on the topic was also conducted. Three data sources from questionnaires, focus group discussions and document analysis enabled a reasonable degree of triangulation (Mgijima, 2014).

\subsection{Instruments}

As discussed elsewhere (Mgijima, 2014), four questionnaires were developed. The first (Tool A), was for the curriculum management teams. The second (Tool B), was for subject lecturers. Both were self-administered at each of the fifty colleges. Then, the third (Tool C), a focus group interview protocol was for the subject lecturers and was facilitated by researchers at a central venue. The fourth (Tool D) was for college managers, also administered by researchers at a different central venue. Data on the professional development needs of college lecturers is reported elsewhere and for purposes of maintaining focus, only findings based on data from managers are reported in this article.

\subsection{Focus Groups}

Focus group discussions were conducted with the managers to encourage a reflective expression of training needs based on actual experiences of the management teams. On the one hand, the intention of the semi-structured questionnaire used in the focus groups was to measure the extent to which college leadership understands its training needs and the ability to articulate these along a continuum of core and generic management competences. On the other hand, the instrument allows for the identification of training needs that are specific to particular areas of operation. The deliberations were carefully documented by means of note-taking. This article reports findings based on the analysis of data from the category of college managers limited to the Eastern Cape Province only.

\subsection{Sampling}

Purposive sampling was followed. In the main study, the aim was to include all 50 colleges in the country. For the management echelon, only the eight FET colleges in the Eastern Cape were targeted for focus group discussions. The target population includes the college principals, deputy principals, campus and programme managers or Heads of Departments. The total sample obtained was 35 , drawn from all eight colleges. 


\subsection{Data Analysis}

The response questionnaires were prepared for data entry, coding and for capturing. Questionnaires were checked for completeness before coding. Data was captured on EXCEL spread - sheets. The SPSS programme was used for processing the quantitative data. Partially filled or questionnaires with non-essential information were discarded. Qualitative data was analysed in accordance with Mouton and Babbie's (2001) methods where data were grouped and categorised into themes and thereafter trends and patterns were derived accordingly. The investigation was to determine what the training needs of the managers were as well as what their preferences were in terms of the design, structure, content and delivery of professional development programmes.

\section{Findings}

The changing FET landscape has given rise to an urgent need for training and development of college managers. Principals reported that their changed responsibilities include providing strategic leadership, student support, marketing, monitoring and evaluation. In addition they must operate as CEOs in relation to the College Councils, and work collaboratively with parents, industry, community and principals of other colleges. In South Africa, there is no policy that requires specialised training for any promotional post in the schools or colleges. Managers are promoted from the ranks of the teaching staff without any preparation or formal induction into the management positions. In the report of a Review of the education system published by the National Planning Commission (2011), it is noted that the expectation to transform the FET colleges to become autonomous entities has been frustrated by the limited capabilities among the majority of college leaders who must drive the transformation process. The investigation on which this article is based sought to determine what skills are needed by the managers in the FET colleges if the performance of these institutions is to improve. The findings arise from three sub-questions: What makes training necessary? What is the most preferred mode of delivery? What type of skills and knowledge are needed by the leaders?

\subsection{Reasons why leadership training is needed}

The article reports on the college level needs which arise out of changes in the organisational structure and organisational operations. The focus group discussions suggested that most managers require upgraded and high-level skills including a full understanding of corporate governance and leadership principles. The most commonly cited reason in terms of this generic training is the pace and scale of change and the range of policy interventions that have been introduced into the system. Seen as compounding the problem is the lack of continuity with major policy initiatives, reversal of policy decisions and pressure to accommodate new strategic priorities associated with changes in government. In the questionnaire, the respondents were asked about the necessity to attend training and to give one most important reason. The majority of respondents (58\%) indicated that they needed to improve their management skills because they were not trained for their positions. In the focus group discussions, some indicated that they "were just promoted from our positions as senior lecturers or heads of departments after applying but once appointed, there was no training to help us with the new responsibilities". Others mentioned that they "did not have the theory of managing because we were trained to teach and without further support we do not always know what to do".

From the background information on the questionnaire, it could be established that the majority of appointments to management levels were made in-house presumably based on good performance in previous lecturing positions. These promotions were made without any skills audits to identify skills needed in the new positions. Selection into promotional posts is based on oral interviews only. Of the reasons for wanting to participate in training, the most popular was a "strong need to improve skills and knowledge" whilst others said they wanted to "be efficient and effective" in their positions as shown in Table 1 below: 
Table 1: Most important reason for participating in training

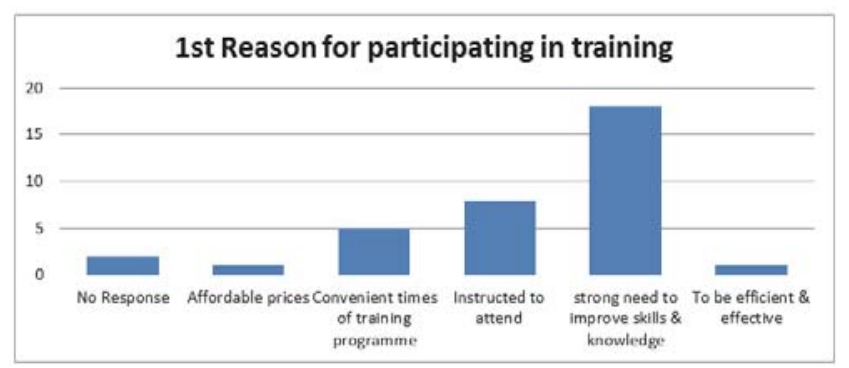

In addition, respondents were required to indicate whether they had participated in any training in the previous year and whether it was an in-house or externally provided training. The findings are presented in Figure 1 below:

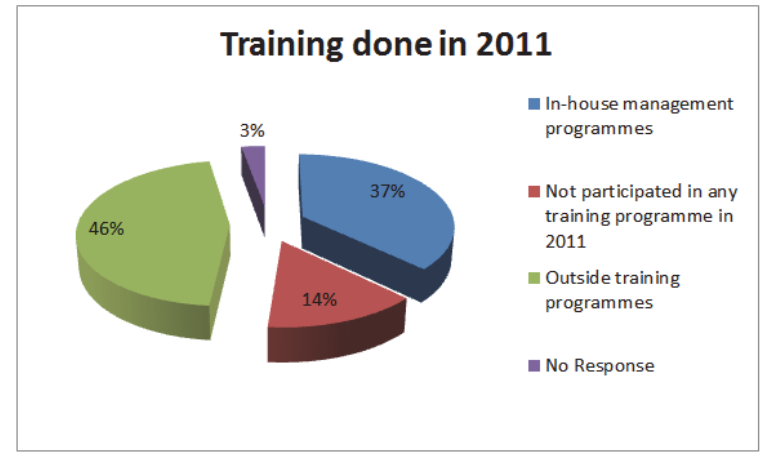

Fig. 1: Participation in training in 2011

It is a concern that $14 \%$ of the respondents indicated that they had not participated in any training in 2011 . This is a significant percentage in view of the problem of lack of management skills across many colleges as discussed above. The majority who attended training (46\%), attended training offered by outside training providers. In the focus group discussion, this was often criticised for non-relevance and difficulty to apply what had been learnt back at the workplace.

\subsection{Preferred programme structure}

In the questionnaire, the respondents were required to indicate their most preferred structure of a training programme. The findings in Fig. 2 below show that $60 \%$ of the respondents wanted a full degree programme as against short-term, non-accredited courses. This is revealing given that in the previous dispensation, college lecturers were not required to have a degree to teach in a technical college. The findings also suggest that criteria for promotion to management positions are not well-defined. The findings further confirm the general perception that FET colleges are failing to attract suitably qualified personnel for a variety of reasons. This is of great significance in a country that has no leadership and management qualification designed for the specific needs of college managers. Neither does the country have structured and accredited CPD programmes for this sector. The responses showed that currently, non-accredited, ad hoc training courses are delivered by some service providers. 


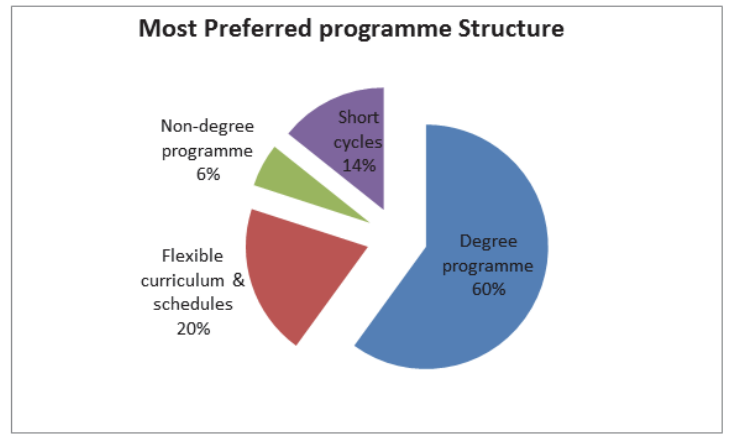

Fig. 2: The most preferred programme structure

The remaining $40 \%$ indicated that they attended a wide range of courses covering such topics as supply chain, financial management, auditing, logistics management, total quality management, Equity Act and other legislation. What must be emphasised is that the selection or participation in these courses was not informed by any training needs analysis. In the focus groups, the participants indicated that it was not easy to "apply what they had learnt as information was not always relevant to the problems in the colleges". As can be gleaned from the list of courses below, participants did not seem to distinguish between training and attendance at any workshop, seminar or event. It only emerged after probing in group discussions that some of these were in fact only information sharing sessions where no learning outcomes were stated or any assessment tasks given. The breakdown of courses attended is reflected in Figure 3 below:

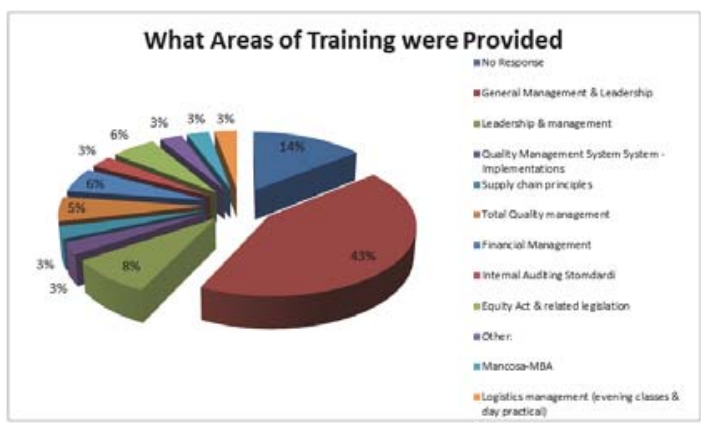

Fig. 3: Areas of training provided

The FET college sub-sector, therefore requires well-structured programmes to give managers a repertoire of skills and knowledge, preferably at advanced levels in order to manage change programmes effectively.

\subsection{Preferred mode of delivery}

In the questionnaire, the respondents were asked to choose whether they preferred to study part-time, attend during holidays and weekends or full-time. Full-time study was most popular among principals, whilst the deputies mostly preferred to study during holidays. Overall, part-time studies would accommodate interests and preferences of the majority. Some of the reasons given in the questionnaire for choosing part-time training include: "Not be disturbed by/or miss out on work; Not to disturb my work days; When not busy at work; Allows me to manage time; Can do other work commitments; To do other things in-between; To ensure that I keep track with my work; Training won't affect my daily operations; Would not want to be away from my work station; After working hours; Avoid interruption of normal duties; Avoiding disturbing college activities; So that they do not interfere with my daily activities; Very committed at work". It is commendable that managers are willing to sacrifice their time during weekends or holidays to study part-time, whilst remaining committed to their day-to-day responsibilities as managers. 
Based on Figure 4 below, it appears that part-time programmes would be able to cater for the preferences of most respondents.

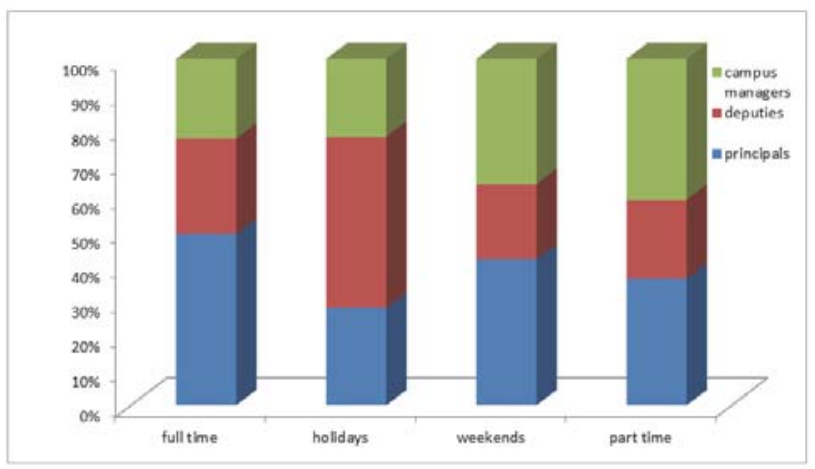

Fig. 4: Preferences on mode of delivery

\subsection{New Training Needs}

The respondents were asked in the questionnaire to select three most important areas where they required training immediately. They were also required to give reasons for their choices. The most common choice was leadership skills. The second most popular was mentoring and coaching, followed by teambuilding skills. Regarding management skills, the majority of respondents chose financial management and auditing skills, then the supply chain management skills, followed by performance management and decision-making skills. In the focus group discussion, the participants were encouraged to emerge with a prioritised list of training needs which was aligned to each occupational category. Through the questionnaire, the needs were further ranked by the different managers in the different categories as presented in Table 2 below:

Table 2: Training priorities by occupational category

\begin{tabular}{|c|l|}
\hline Occupation & \multicolumn{1}{|c|}{ Priority area for training } \\
\hline Principal & $\begin{array}{l}\text { Project management; monitoring and evaluation; change management; financial management; conflict and } \\
\text { stakeholder management; understanding college statutes; policies and legislation; research methods; } \\
\text { diversity management; team-building; advanced computer skills; strategic planning; Human Resource } \\
\text { Administration; risk management }\end{array}$ \\
\hline Deputy Principal & $\begin{array}{l}\text { Strategic planning; accountability measures; managing performance; mentoring and coaching; quality } \\
\text { assurance; project management; communication skills; monitoring and evaluation; conflict management; report } \\
\text { writing; policy development; financial management; stress management; governance and legislation; planning } \\
\text { and budgeting; marketing and advocacy; advanced data management; curriculum delivery, learning and } \\
\text { assessments }\end{array}$ \\
\hline Campus Manager & $\begin{array}{l}\text { Labour relations; leadership; asset management; supply chain management; Human Resource Administration } \\
\text { and Management; governance and legislation }\end{array}$ \\
\hline $\begin{array}{l}\text { Programme Manager } \\
\text { /Head of Department }\end{array}$ & $\begin{array}{l}\text { Communication; monitoring and evaluation; report writing; curriculum design; research Skills; curriculum } \\
\text { design and planning; supervision and support; performance management }\end{array}$ \\
\hline
\end{tabular}

This shows a very wide range of training needs which is symptomatic of severe gaps in management and leadership skills. It would be necessary to prioritise the training needs on the basis of the key performance areas of managers in their respective positions.

\section{Discussion}

The importance role of leaders in managing change cannot be overemphasised. Their skills and knowledge should be at par with the responsibilities and activities they have to carry out. To develop and sustain competences, it is essential that organisations continuously renew the expertise of individuals as they reflect on their relevance given the changes in the 
operational environment. A competency framework is needed to serve as the tool for planning and designing professional development programmes. This implies redefinition of leadership responsibilities across the management echelons of the colleges taking into consideration the major domains of responsibility associated with distributed leadership. Leadership development needs to be approached as a continuum that starts with foundational generic skills and knowledge and progressively branch out to job specific skills. Induction programmes for new leaders should be designed or strengthened and formalised. Table 2 above shows overlaps and evidence of uncertainty in terms of roles and responsibilities amongst managers. Ways to distinguish roles of principals as CEOs and accounting officers of the colleges should be found. For the rest, expertise rather than position should determine how responsibilities are assigned. It would be necessary for the Department of Higher Education and Training (DHET) to consider ways of redesigning accountability mechanisms to be aligned with the distributed leadership positions.

Although the concept of effective leadership or management is not easy to define, equipping college managers with relevant and adequate skills and knowledge should go a long way to improve the performance of colleges. This is an immediate challenge for policy-makers because none of the higher education institutions in the country has a training programme that is tailor-made to suit the needs as expressed by the college managers. Therefore, the DHET should collaborate with a range of public and private training providers in designing appropriate initial training and CPD programmes for college managers.

The systems view emphasises that leadership training is an inherent part of the change process, and that it has to be planned for. The DHET seems to have overlooked this critical aspect when mapping the transformation of the FET colleges. As gleaned from the findings, whatever leadership training is happening currently, it is ad hoc. It is therefore necessary to restructure training into professional learning programmes that are delivered on an on-going basis. The identified training needs should form the basis of the design of the new CPD programmes. Comparing information in Fig. 3 and Table 2 above, it is evident that there are significant discrepancies in terms of what managers perceive as their priority training needs and what is currently available to them. This suggests a situation where there is a lack of synergy and coordination of activities carried out at the policy-making level and at the different levels of the system. In other words, the piecemeal, rather than a holistic approach seems detrimental to the effective development of leadership capacity in the FET colleges.

Given the urgency to deliver CPD programmes, a collaborative approach could be adopted using partnerships, networks and communities of learning. This model would promote both a culture of reflective professional inquiry as well as a collective responsibility in the skills development process. As already envisaged, the DHET could, together with other partners, set up the necessary institutional infrastructure for the long-term sustainability of this intervention. The intervention could be on two clusters of priority areas, namely organisational development and operational effectiveness. The first would focus on vision crafting, changing culture, networking and inter-personal relationships. The second would address issues such as professional development, research and data collection for performance monitoring and evaluation.

\section{Conclusion}

The above analytical account shows that the speed with which policy changes have happened at the macro-level of the system has not allowed the college sub-system to mature, stabilise and become a viable sector that can effectively manage the delivery of its programmes. What has emerged is the need to redefine notion of training and development for managers who have gained added responsibilities and prepare them to become professional managers responsible for leading and managing learning organisations. As a redress mechanism, improving the capabilities of all managers in the FET colleges through well-structured and relevant CPD programmes whose effectiveness is measurable will help build a system of post school education and training that is worthy of the huge investment made in it. The establishment of Professional Learning Communities (PLCS) should underpin the strategy. As Sullivan, Kashiwagi and Lines argue, it is the effectiveness with which organisations manage change that has become a critical element in their ability to maintain a long-term competitive edge (2011:302).

\section{References}

Bolam, R. (1997). Management Development for Headteachers: Retrospect and Prospect. Educational Management and Administration. Vol.25 (3) 265-283.

Dalin, P. (1978). Limits to Educational Change. Macmillan, London.

Department of Education. (2008). National Further Education and Training Plan. Government Printers, Pretoria. 
Descombe, M. (2008). Communities of Practices: A research Paradigm for the Mixed Methods Approach. Journal of Mixed Methods Research, Vol.2, 270-283.

Gadja, R. \& Koliba, C. (2007). Evaluating the Imperative of Intra-organisational Collaboration: A School Improvement Perspective.

Gewer, A. (2010). Improving quality and expanding the further education and training college system to meet the need for an inclusive growth path. Development Bank of Southern Africa. South Africa.

Government of South Africa (1998). Further Education and Training Act, (Act No. 98 of 1998). Government Printers, Pretoria.

Hallinger, P \& Heck, R.H. (2011). Exploring the journey of school improvement: classifying and analysing patterns of change in school improvement processes and learning outcomes. School Effectiveness and School Improvement: An International Journal of Research, Policy and Practice. Vol.22 (1), 1-27

Harman, G. (1983). Research on Institutional Amalgamation in Tertiary Education: Concepts, Classificatory Schemes and Relevant Literature. Journal of Tertiary Educational Administration, Vol.5 (2), 113-129.

Harman, K. and Meek, L.V. (2002). Merger Revisited: International perspectives on mergers in Higher Education. Higher Education. Kluwer Academic Publishers, Netherlands.

Harman, G. S. \& Robertson-Cunninghame, R. (Eds). (1995) the Network UNE Experience: Reflections on the Amalgamated University of New England, 1989-1993. Department of Administrative, Higher \& Adult Education Studies.

Insitute for Learning (IFL). (2010). Guidelines for Continuing Professional Development (CPD), UK

Johnson, R. B., Onwuegbuzie, A.J. and Turner, L. A. 2007. Toward a Definition of Mixed Methods Research. Journal of Mixed Methods Research, Vol.1, 112-133.

Meyer, M. (ed.) (2007). Human Resource Development: An Outcomes-based Approach. $3^{\text {rd }}$ Edition. LexisNexis. South Africa.

Mgijima M. (1991). Implementing Educational Innovations: The case of the Secondary School Curriculum Diversification Programme in Lesotho. Unpublished PhD thesis.

Mgijima, N. (2014). Needs-based professional development of lecturers in the Further Education and Training Colleges: A Strategic imperative. The Mediterranean Journal of Social Sciences. Vol.5 (2), 359-369

Mouton, J. \& Babbie, E. (2001). The practice of social research. Cape Town: Wadsworth Publishing Company.

National Planning Commission. (2011). Diagnostic Report. Report presented to Parliament South Africa. Government Printers, Pretoria.

Potter, M. A., Barron, G. and Cioffi, P. J. (2003). A model for Public Health Workforce Development Using the National Public Health Performance Standards Program. Journal for Public Health Management Practice, Vol.9 (3), 199-207.

Schoech, D. (2004). Concept Paper: Systems Theory. Available at: www2.uta.edu/cussn/courses/5306/coursepack/theory-systems.

Senge, P. M. (1990). The Fifth Discipline. New York Currency Double-day.

Skodvin, O. J. (1997). The Reorganisation of non-university higher education in Norway: Problems and potentials. Tertiary Education and Management, Vol.3 (4), 317-324.

Sullivan, K., Kashiwagi, D. \& Lines, B. (2011). Organisational Change Models: A Critical Review of Change Management Processes. RICS Construction and Property Conference.

Timperly, H. S. (2005). Distributed Leadership: Developing theory from practice. Journal of Curriculum Studies, 37(4), 395-420

Volmari, K, Helakorpi S, and Frimodt (ed). (2009). Competence Framework for VET Professions: Handbook for practitioners. European Centre for the Development of Vocational Training

Watson, L. (2009). Issues in Reinventing School Leadership: Reviewing the OECD report on improving school leadership from an Australian perspective. Leading and Managing, Vol.15 (1) 1-13.

Wilcox, J. (2010). Initial and Continuing Professional Development of Teachers. Teacher Training Agency, United Kingdom. 